generation of scientists that will be able to study the quickly disappearing examples of primitive man. The simple fact is that at present we know virtually nothing about how selection works in man. One way of understanding the genetic impact of our rapidly changing environment is from the baseline supplied by detailed knowledge of primitive man in his primitive ecosystem".

Studies among the Yanomama Indians of Venezuela and Brazil have already revealed a remarkable degree of genetic differentiation between villages, thought to be the result of the fission-fusion pattern which dominates village proliferation. Work with transitional groups also shows that rapid and subtle changes take place in the health of communities subjected to even quite small changes of environment. A high incidence of gallstones and diabetes is a feature of such Indian groups and is well documented from the south-western United States. Moreover, there is a shift in the type of intestinal microflora after contact with civilization. The accident proneness common among Indians in contact with Western civilization has yet to be explained. In his summing up Dr Neel noted that, whereas "we tend to view many of these surviving primitive groups as representing extremes of adaptability, they have lived under their conditions far longer than we under ours, and it is only an act of faith that we will adapt to our man-made environment as successfully as they to theirs".

\section{Patients Without Care}

The unhappy plight of out-patients in British hospitals is well documented in a report published on July 18 by Mr Gordon Forsyth and Dr R. F. L. Logan for the Medical Care Research Unit at the University of Manchester (Gateway or Dividing Line, OUP, 21s.). The report is based on a survey of 13,600 out-patients referred for the first time to clinics in eleven groups of hospitals in England and Wales, and therefore covers about $0 \cdot 3$ per cent of the five million people who attend hospital each year as out-patients. Between them, the 80 hospitals selected for the survey serve about two million people. The report has the merit of showing precisely where the function and management of out-patient departments fail and speculates, albeit cautiously, on how the present structure might be improved.

Even where trivialities are concerned, the report reveals that the out-patient service leaves much to be desired. Signposting for out-patients is frequently absent or ambiguous. Toilet facilities are often inadequate. More often than not, the appointments system breaks down because hospitals tend to overbook at the beginning of a clinic to ensure against non-arrival or lateness of patients. In a nutshell, "scant regard is paid either to natural anxieties experienced by patients, or to basic human dignity". Much of the trouble, the report suggests, stems from ambiguities about responsibility for day to day management of departments.

A more serious charge is that departments often fail to carry out adequate clinical investigation. Thus laboratory tests were not carried out on half the patients in the survey with peptic ulcers. A quarter of those with menstrual disorders were similarly neglected. Not one of the departments visited had its own out. patient theatre for minor surgical operations. The authors of the report say that there is inadequate communication between consultants and the referring general practitioners, and that appointments are often needlessly delayed. Another criticism in the report is that little cross-referral takes place between specialties in the clinics and that patients are rarely referred to medical social workers.

In view of the crammed programme of which consultants complain, Mr Forsyth and Dr Logan question the nonsensical prolonged attendance at out-patient departments of patients with minor complaints such as common prolapse. Consultants questioned during the survey seem to have had the impression that general practitioners ask for specialist help too readily, and they would like to see more junior hospital medical staff assisting in out-patient departments. What, then, is to be done? Mr Forsyth and Dr Logan offer little advice in this connexion, but do fly the old kite for opening hospital facilities to general practitioners. They also emphasize the need to make a continuous review of the referral of patients, and suggest that consultant units may have to give way to area specialist departments under chiefs of service who would take over many of the responsibilities of the laymen who often, at present, find hospital administration too exacting.

\section{Flood Research}

A GRant for the study of flood control in Britain was announced last week by Mr Edward Short, the Secretary of State for Education and Science, during a visit to the Institute of Hydrology. The study will cost $£ 250,000$, and will be conducted in collaboration with the Water Resources Board during the next three to five years. The minister stated that the problem of flood control must be tackled much more efficiently and scientifically than it has been until now, and hoped that this study would lead to nation-wide standards. Part of the study will be to analyse data from the various river flood boards in order to give an accurate basis for decisions in the future. At present, decisions on such engineering problems as bridge heights and river bank reinforcements must be made in a haphazard way because of a lack of accurate data, the minister added, and the study will help to define the programme of research needed to produce the design data required by civil engineers for flood control.

The institute, which comes under the aegis of the Natural Environment Research Council, already studies all aspects of hydrology-precipitation, stream flow, evaporation and storage changes within the soil and bedrock, soil physics, geology and micrometeorologyand is concerned with drought as well as flood. $\mathrm{Mr}$ Short noted that "water shortage for domestic and industrial use is already apparent, particularly in the south-east, and is likely to become so serious as to impair development of the area in the not too distant future".

In an attempt to learn more about the factors that control river flow, the institute is studying seven "catchment areas" or river basins, measuring rainfall, evaporation and storage changes in the soil and bedrock in order to understand the water balance under different soil and land use conditions. To simplify these 